\title{
Anti-Cancer Effect of the Combination of Thiacremonone and Docetaxel by Inactivation of NF-kB in Human Cancer Cells
}

\author{
Jung Ok BaN ${ }^{1,2}$, Jin Suk $\mathrm{CHO}^{1}$, In Guk HWANG ${ }^{3}$, Jin Woo $\mathrm{NOH}^{3}$, Wun-Jae KIm ${ }^{4}$, \\ Ung Soo LeE ${ }^{5}$, Dong Cheul Moon ${ }^{1}$, Heon-Sang JeONG ${ }^{3}$, Hee Soon LeE ${ }^{1,2}$, \\ Bang Yeon HWANG ${ }^{1}$, Jae-Kyung Jung ${ }^{1,2}$, Sang Bae $\mathrm{HAN}^{1,2}$, and Jin Tae HoNG ${ }^{1,2, *}$ \\ ${ }^{1}$ College of Pharmacy, ${ }^{2}$ Medical Research Center, ${ }^{3}$ College of Agriculture, Life and Environments Sciences, \\ ${ }^{4}$ Departments of Urology and Biochemistry (SCB), College of Medicine, Institute for Tumor Research, \\ ${ }^{5}$ Department of Food and Biotechnology, Chungju National University, Chungju 380-702, Republic of Korea
}

(Received September 21, 2009; Revised October 14, 2009; Accepted October 9, 2009)

\begin{abstract}
Thiacremonone, the main component isolated from heated garlic (Allium sativum L.), is interested for using as a cancer preventive or therapeutic agent since garlic has been known to be useful plant in the treatment of cancers. Nuclear factor kappaB $(\mathrm{NF}-\mathrm{kB})$ is constitutively activated in the prostate cancer and activation of NF-kB is implicated in drug resistance in cancer cells. Docetaxel, a semisynthetic analog of paclitaxel, is an antineoplastic drug widely used for advanced various cancer. In previous studies, we found that thiacremonone inhibited activation of NF-kB in cancer cells and marcrophages. In the present study, we investigated whether thiacremonone could increase susceptibility of prostate cancer cells (PC-3 and DU145) to docetaxel via inactivation of NF-kB. We found that the combination treatment of thiacremonone $(50 \mu \mathrm{g} / \mathrm{ml})$ with docetaxel $(5 \mathrm{nM})$ was more effective in the inhibition of prostate cancer cell growth and induction of apoptosis accompanied with the significant inhibition of NF-kB activity than those by the treatment of thiacremonone or docetaxel alone. It was also found that NF-kB target gene expression of Bax, caspase-3 and caspase- 9 was much more significantly enhanced, but the expression of $\mathrm{Bcl}-2$ was also much more significantly inhibited by the combination treatment. These results indicate that thiacremonone inhibits NF-kB, and enhances the susceptibility of prostate cancer cells to docetaxel. Thus, thiacremonone could be useful as an adjuvant anti-cancer agent.
\end{abstract}

Keywords: Thiacremonone, Docetaxel, NF-kB, Apoptotic cell death, Prostate cancer

\section{INTRODUCTION}

Although combination therapy for prostate cancer has been demonstrated to improve survival compared with previous standards of treatment, the regimen is not curative. In efforts to identify better therapeutic strategies that would improve drug efficacy and reduce side effects, target oriented combination therapies with natural compound have been demonstrated (Ortiz et al., 2002). In previous studies, we reported that thiacremonone, a sulfurcompond isolated from heated garlic, inhibited nuclear factor kappaB (NF-kB) and cancer cell growth with $\mathrm{IC}_{50}$ values about $100 \mu \mathrm{g} / \mathrm{ml}$ in colon cancer cells (Ban et al.,

${ }^{*}$ Corresponding author

Tel: +82-43-261-1813 Fax: +82-43-268-2732

E-mail: jinthong@chungbuk.ac.kr
2007). We also demonstrated that thiacremonone augmented chemotherapeutic agents-induced growth inhibition in human colon cancer cells through inactivation of NF-kB (Ban et al., 2009). NF-kB has been known to be constitutively activated in various human cancers and it is implicated in drug resistance (Wang and Cassidy, 2003). NF-KB was shown to be constitutively activated in human prostate cancer cell (Palayoor et al., 1999). Moreover, several reports have suggested that chemotherapeutics- induced NF- $\mathrm{kB}$ activity mediates survival signals that counteract apoptosis (Dong et al., 2002; Uzzo et al., 2002). Therefore, several agents that are able to inhibit NF-kB might be considered as an adjuvant approach in combination with chemotherapeutics for various cancers including prostate cancer (Zhang et al., 2003; Yance and Sager, 2006). 
Docetaxel, a semisynthetic taxoid produced from the needles of the European yew (Taxus baccata) tree, is one of the most important active chemotherapeutic agents for human prostate cancers (Diaz-Rubio, 2004). However, the use of high-dose docetaxel induce significant toxicities such as asthenia, neuropathy, vertigo and tinnitus (Sarafraz and Ahmadi, 2008; Baker et al., 2009), whereas lowdose of docetaxel have no significant antitumor activity in patients (Ryan et al., 2002).

Several sulfurcompounds, such as diallyl disulfide and S-trityl-L-cysteine isolated from garlic, have been known to be effective in chemoprevention. These compounds have also been shown to inhibit cancer cell growth and/or to induce cell death in several human cancer cells including breast and hepatoma as well as lung cancer cells (Nakagawa et al., 2001; Sabayan et al., 2007).

In this regard, dietary supplements as well as phytotherapeutic agents with anticancer efficacy and less toxicity to normsal tissues are suggested as possible candidates to be used in combination with anticancer drugs (Kelloff, 2000; Sporn and Suh, 2000). These data indicate that thiacremonone could be useful chemosensitizer through inactivation of NF-kB.

\section{MATERIALS AND METHODS}

\section{Materials}

Thiacremonone, a novel sulfur compound from garlic was isolated and identified as described elsewhere (Kwon et al., 2006; Hwang et al., 2007). The structure of thiacremonone is shown in Fig. $1 \mathrm{~A}$. Thiacremonone was resolved in $0.01 \%$ dimethyl sulfoxide (DMSO), and administered in a dose of $50 \mu \mathrm{g} / \mathrm{ml}$. Docetaxel was obtained from Samyang genex corporation (Daejeon, Korea). Docetaxel was produced by semisynthesis and purification methods (Ojima et al., 1996). Briefly, crude docetaxel was obtained from semisynthesis of 13Dehydroxybaccatin III with (3R, 4S)-1-t-Boc-3-triethylsilyloxy-4-phenylazetidin-2-one as a Docetaxel side chain, and then purified by recrystallization with $\mathrm{MeOH} / \mathrm{DW}$

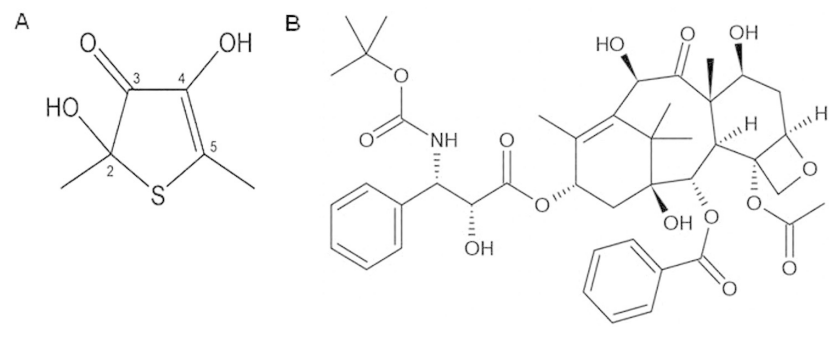

Fig. 1. Structure of thiacremonone (A) and docetaxel (B). solution. The structure of Docetaxel is shown in Fig. 1B. Docetaxel was dissolved in $0.01 \%$ DMSO for treatment in vitro.

\section{Cell culture}

Prostate (PC-3 and DU145) cells were obtained from the American Type Culture Collection (Manassas, VA 20108, USA). RPMI1640, penicillin, streptomycin, and fetal bovine serum were purchased from Gibco Life Technologies (Grand Island, NY, USA). Prostate cancer cells were grown in RPMl1640 medium with $10 \%$ fetal bovine serum, $100 \mathrm{U} / \mathrm{ml}$ penicillin, and $100 \mu \mathrm{g} / \mathrm{ml}$ streptomycin at $37^{\circ} \mathrm{C}$ in $5 \% \mathrm{CO}_{2}$ humidified air.

\section{Cell viability assay}

To determine the cell number, prostate cancer cells were plated onto 24 -well plates $\left(5 \times 10^{4}\right.$ cells/well), and were trypsinized and pelleted by centrifugation for $5 \mathrm{~min}$ at $1,500 \mathrm{rpm}$, resuspended in $10 \mathrm{ml}$ of phosphate-buffered saline (PBS), and $0.1 \mathrm{ml}$ of $0.2 \%$ trypan blue was added to the cancer cell suspension in each of the solutions $(0.9 \mathrm{ml}$ each). Subsequently, a drop of suspension was placed into a Neubauer chamber and the living cancer cells were counted. Cells that showed signs of staining were considered to be dead, whereas those that excluded trypan blue were considered viable. Each assay was carried out in triplicate.

\section{Western blot analysis}

Cultured cells were washed twice with $1 \times \mathrm{PBS}$, followed by the addition of $1 \mathrm{ml}$ of PBS, and the cells were scraped into a cold Eppendorf tube. Cells were homogenized with lysis buffer $[50 \mathrm{mM}$ Tris pH 8.0, $150 \mathrm{mM} \mathrm{NaCl}, 0.02 \%$ sodium azide, $0.2 \%$ sodium dodecyl sulfate (SDS), $1 \mathrm{mM}$ phenylmethanesulfonyl fluoride (PMFS), $10 \mu \mathrm{l} / \mathrm{ml}$ aprotinin, 1\% igapel 630 (Sigma Chem. Co. St. Louis, MO, USA), $10 \mathrm{mM} \mathrm{NaF}, 0.5 \mathrm{mM}$ ethylene diamine tetraacetic acid (EDTA), $0.1 \mathrm{mM}$ ethylene glycol tetraacetic acid (EGTA) and $0.5 \%$ sodium deoxycholate], and centrifuged at $23,000 \mathrm{~g}$ for $1 \mathrm{~h}$. The protein concentration was measured by the Bradford method (Bio-Rad Protein Assay, Bio-Rad Laboratories Inc, Hercules, CA), and equal amount of proteins $(40 \mu \mathrm{g})$ were separated on a SDS/1\%-polyacrylamide gel, and then transferred to a nitrocellulose membrane (Hybond ECL, Amersham Pharmacia Biotech Inc., Piscataway, NJ, USA). Blots were blocked for $2 \mathrm{~h}$ at room temperature with 5\% (w/v) non-fat dried milk in Tris-buffered saline [10 mM Tris ( $\mathrm{pH} \mathrm{8.0)}$ and $150 \mathrm{mM} \mathrm{NaCl}$ s solution containing $0.05 \%$ tween-20. The membranes were immunoblotted with primary specific 
antibodies: rabbit polyclonal for Bax (1:500 dilution, Santa Cruz Biotechnology Inc. Santa Cruz, CA, USA), caspase-3, caspase-9, Bcl-2 (1:1,000 dilution, Cell Signaling Technology Inc., Beverly, MA, USA). The blot was then incubated with the corresponding conjugated anti-rabbit immunoglobulin G-horseradish peroxidase (1:2,000 dilution, Santa Cruz Biotechnology Inc.). Immunoreactive proteins were detected with the enhanced chemiluminescence (ECL) western blotting detection system. The relative density of the protein bands was scanned by densitometry using Mylmage (SLB, Seoul, Korea), and quantified by Labworks 4.0 software (UVP Inc., Upland, CA, USA).

\section{Gel electromobility shift assay}

Gel shift assays were performed according to the manufacturer's recommendations (Promega, Madison, WI, USA). Briefly, $2 \times 10^{6}$ cells $/ \mathrm{ml}$ was washed twice with $1 \times$ PBS, followed by the addition of $1 \mathrm{ml}$ of PBS, and the cells were scraped into a cold eppendorf tube. Cells were spun down at $15,000 \mathrm{~g}$ for $1 \mathrm{~min}$, and the resulting supernatant was removed. Solution A (50 mM 4-(2-hydroxyethyl)1-piperazineethanesulfonic acid (HEPES), pH 7.4, $10 \mathrm{mM}$ $\mathrm{KCl}, 1 \mathrm{mM}$ EDTA, $1 \mathrm{mM}$ EGTA, $1 \mathrm{mM}$ dithiothreitol (DTT), $0.1 \mu \mathrm{g} / \mathrm{ml} \mathrm{PMFS}, 1 \mu \mathrm{g} / \mathrm{ml}$ pepstatin A, $1 \mu \mathrm{g} / \mathrm{ml}$ leupeptin, 10 $\mu \mathrm{g} / \mathrm{ml}$ soybean trypsin inhibitor, $10 \mu \mathrm{g} / \mathrm{ml}$ aprotinin, and $0.5 \%$ Nonidet P-40) was added to the pellet in a 2:1 ratio $(\mathrm{v} / \mathrm{v})$ and allowed to incubate on ice for $10 \mathrm{~min}$. Solution $\mathrm{C}$ (solution $\mathrm{A}+10 \%$ glycerol and $400 \mathrm{mM} \mathrm{KCl}$ ) was added to the pellet in a 2:1 ratio $(\mathrm{v} / \mathrm{v})$, and vortexes on ice for $20 \mathrm{~min}$. The cells were centrifuged at $15,000 \mathrm{~g}$ for $7 \mathrm{~min}$, and the resulting nuclear extract supernatant was collected in a chilled Eppendorf tube. Consensus oligonucleotides were end-labeled using T4 polynucleotide kinase and $\left[\gamma-\mathrm{P}^{32}\right]$ ATP for $10 \mathrm{~min}$ at $37^{\circ} \mathrm{C}$. Gel shift reactions were assembled and allowed to incubate at $37^{\circ} \mathrm{C}$ for $10 \mathrm{~min}$ followed by the addition of $1 \mu \mathrm{l}(50,000-200,000 \mathrm{cpm})$ of $\left[\gamma-\mathrm{P}^{32}\right]$ ATP-labeled oligonucleotide and another $20 \mathrm{~min}$ of incubation at $37^{\circ} \mathrm{C}$. Subsequently $1 \mu \mathrm{l}$ of gel loading buffer was added to each reaction and loaded onto a $4 \%$ nondenaturing gel and electrophoresis until the dye was three-fourths of the way down the gel. The gel was dried at $80^{\circ} \mathrm{C}$ for $1 \mathrm{~h}$ and exposed to film overnight at $-70^{\circ} \mathrm{C}$. The relative density of the protein bands was scanned by densitometry using Mylmage, and quantified by Labworks 4.0 software (UVP Inc.).

\section{Transfection and assay of luciferase activity}

Prostate cancer cells $\left(5 \times 10^{4}\right.$ cells/well $)$ were plated in 24-well plates and transiently transfected with pNF-kB-Luc plasmid ( $5 \times \mathrm{NF}-\mathrm{kB}$; Stratagene, $\mathrm{CA}, \mathrm{USA})$ using a mixture of plasmid and WelFect-EX Plus transfection reagent (WelGENE, Seoul, Korea) according to the manufacture's protocol. The transfected cells were treated with docetaxel $5 \mathrm{nM}$ and thiacremonone $50 \mu \mathrm{g} / \mathrm{ml}$ for $8 \mathrm{~h}$. Luciferase activity was measured by using the luciferase assay kit (Promega, Madison, WI, USA) according to the manufacturer's instructions.

\section{Detection of apoptosis}

Prostate cancer cells $\left(1 \times 10^{4}\right.$ cells/well $)$ were cultured on a chamber slide (Lab-Tak II chamber slider system, Nalge Nunc Int., Naperville, IL, USA), fixed in $4 \%$ paraformaldehyde, membrane-permeabilized by exposure for $30 \mathrm{~min}$ to $0.1 \%$ Triton $X-100$ in phosphate-buffered saline at room temperature. TdT-mediated dUTP nick and labeling (TUNEL) assays were performed by using the in situ cell death detection kit (Roche Diagnostics GmbH, MannheiM, Germany) according to manufacturer's instructions. For 4, 6-diamino-2-phenylindole (DAPI) staining, slides were incubated for $30 \mathrm{~min}$ at room temperature in the dark with mounting medium for fluorescence with containing the DAPI (Vectoer Laboratories, Inc., Burlingame, $\mathrm{CA})$. The cells were then observed through a fluorescence microscope (Leica Microsystems AG, Wetzlar, Germany). Total number of cells in given area was determined by using DAPI nuclear staining. The apoptotic index was determined as the number of DAPI-stained TUNEL-positive stained cells divided by the total cell number counted $\times 100$.

\section{Statistics}

Data were analyzed using GraphPad Prism 4 software (Version 4.03, GraphPad software, Inc.). Data were assessed by one-way analysis of variance (ANOVA). If the $p$ value in the ANOVA test was significant, the differences ( $p$ $<0.05$ ) between pair of means were assessed by the Dunnet's test. Data are presented as mean \pm S.D. from three independent experiments with triplicates.

\section{RESULTS}

\section{Effect of the combination of thiacremonone and docetaxel on the NF-KB activation in prostate cancer cells}

$\mathrm{NF}-\kappa \mathrm{B}$ is a critical in prostate cancer cell survival and resistance against chemotherapeutics. In previous studies, we reported that thiacremonone inhibited activation of $\mathrm{NF}-\kappa \mathrm{B}$ in colon cancer cells in a dose dependent manner (Ban et al., 2007). We also reported that the treatment of docetaxel slightly changed (either increase or decrease) the constitutively activation of NF- $\mathrm{kB}$ DNA binding activity 
A

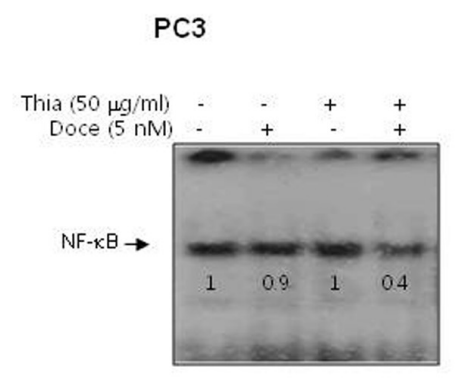

DU145

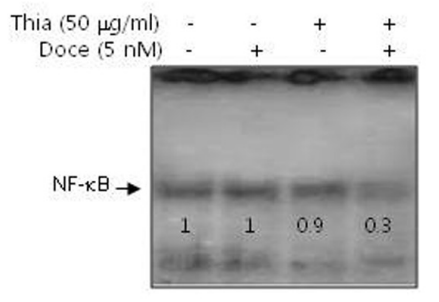

B

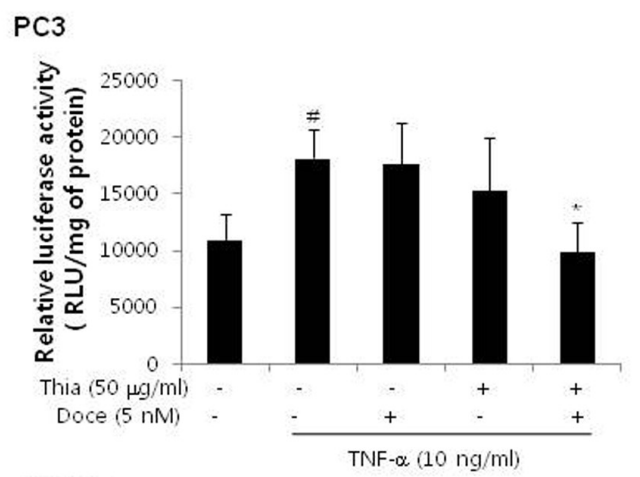

DU145

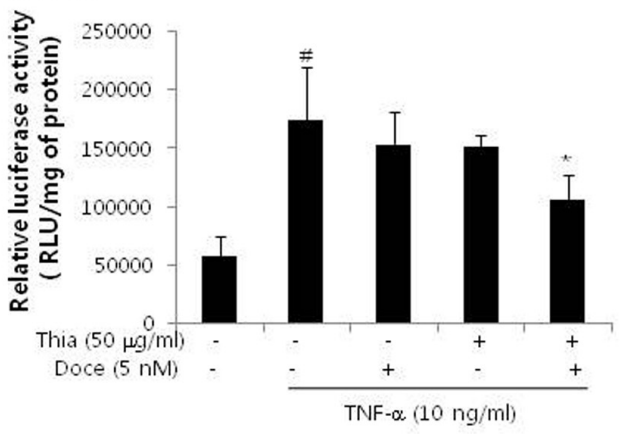

Fig. 2. Effect of the combination treatment of thiacremonone and docetaxel on the NF- $\kappa B$ DNA binding (A) and transcriptional activity activation (B) in prostate cancer cells. (A) Nuclear extract from prostate cancer cells co-treated with $50 \mu \mathrm{g} / \mathrm{ml}$ thiacremonone and $5 \mathrm{nM}$ docetaxel for $1 \mathrm{~h}$ was incubated in binding reactions of ${ }^{32} \mathrm{P}$-end-labeled oligonucleotide containing the $\kappa \mathrm{B}$ sequence. Quantification of band intensities from three independent experimental results performed by densitometry (Imaging System) and the value under each band indicated as fold difference from the untreated control group. (B) Prostate cancer cells were transfected with pNF- $\kappa \mathrm{B}-\mathrm{Luc}$ plasmid $(5 \times \mathrm{NF}-\kappa \mathrm{B})$ for $6 \mathrm{~h}$. The transfected cells were incubated with fresh medium containing co-treated with $50 \mu \mathrm{g} / \mathrm{ml}$ thiacremonone and $5 \mathrm{nM}$ docetaxel for $8 \mathrm{~h}$. All values represent means \pm S.D. of three independent experiments performed in triplicate. RLU is relative to luciferase activity in unstimulated cells. ${ }^{\#} p<0.05$ indicates statistically significant differences from the control group. ${ }^{*} p<0.05$ indicates statistically significant differences from the normal group.

by 1 or $5 \mathrm{nM}$ of docetaxel in PC-3 and DU145, and then decreased by $10 \mathrm{nM}$ docetaxel as similar to the previous report (Kim et al., 2009). However, the combination of $5 \mathrm{nM}$ docetaxel and $50 \mu \mathrm{g} / \mathrm{ml}$ thiacremonone significantly inhibited the constitutively activated NF-KB DNA binding activity (Fig. 2A). The combination effect of thiacremonone with docetaxel on the TNF- $\alpha$-induced NF-kB-dependent reporter gene expression was also determined in the transiently transfected cells with NF-kB-regulated luciferase reporter construct after stimulation of TNF- $\alpha(10 \mathrm{ng} / \mathrm{ml})$ to activate transcriptional activity of NF- $\mathrm{\kappa B}$. The combination significantly inhibited the transcriptional activity of NF- $\mathrm{\kappa B}$, whereas the treatment of docetaxel or thiacremonone alone slightly decreased (Fig. 2B).

\section{Thiacremonone sensitizes prostate cancer cells to docetaxel}

To examine whether the inhibitory effect of the combi- nation of thiacremonone and docetaxel on NF-kB activity could result in prostate cancer cell growth inhibition, we analyzed cancer cell growth inhibition by the combination treatment. Our previous data show a concentrationdependent inhibition of cell growth by thiacremonone alone treatment in prostate cancer cells with $\mathrm{IC}_{50}$ values, 210 and $190 \mu \mathrm{g} / \mathrm{ml}$ in PC-3 and DU145 cancer cells after $24 \mathrm{~h}$ treatment, respectively (data not shown). Docetaxel treatment for $24 \mathrm{~h}$ also inhibited cancer cell growth in a concentration dependent manner with $\mathrm{IC}_{50}$ values about 12 and $14 \mathrm{nM}$ in PC-3 and DU145 cancer cells, respectiviely (Kim et al., 2009). Subsequent studies were undertaken to examine whether the prostate cancer cells were more sensitive to the cytotoxic effect by the combined regimen of thiacremonone $(50 \mu \mathrm{g} / \mathrm{ml}, 1 / 4$ dose of $\left.\mathrm{IC}_{50}\right)$ with docetaxel $\left(5 \mathrm{nM}\right.$, less than half dose of $\mathrm{IC}_{50}$ value). The combination treatment resulted in a significant inhibitory effect on prostate cancer cell growth, whereas 
A

$\mathrm{PC3}$

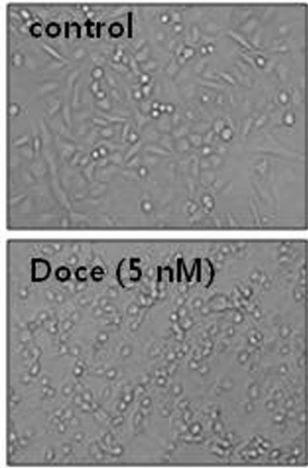

DU145
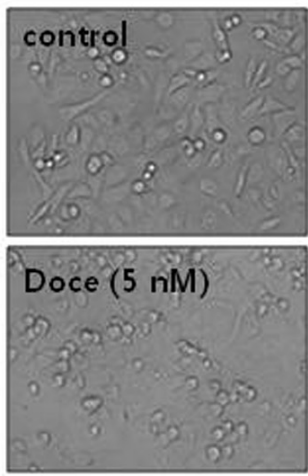

B

PC3

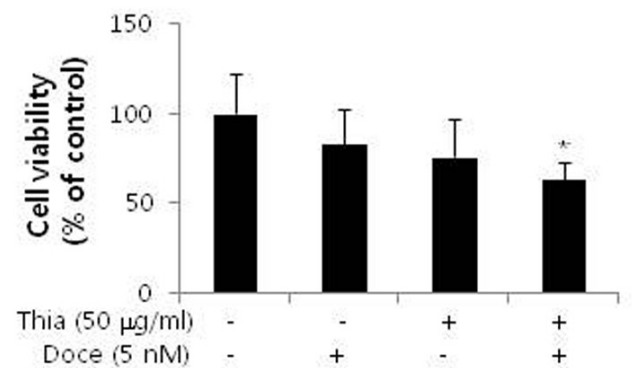

DU145

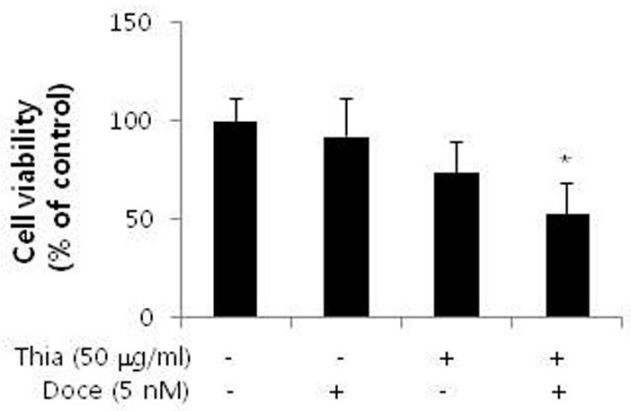

Fig. 3. Effect of the combination treatment of thiacremonone and docetaxel on the morphological changes $(A)$ and cell viability $(B)$ in prostate cancer cells. Prostate cancer cells were treated with thiacremonone or docetaxel or co-treated with $50 \mu \mathrm{g} / \mathrm{ml}$ thiacremonone and $5 \mathrm{nM}$ docetaxel combination. (A) Morphorogical changes were observed under microscope. (B) Cell viability was determined after $24 \mathrm{~h}$ culture by direct cell counting using trypan blue as described in Materials and Methods, and the results were expressed as percentage of viable cells. Values are each the mean \pm S.D. of three experiments, each performed in triplicate. Bar indicates $100 \mu \mathrm{m}$. ${ }^{*} p<0.05$ indicates statistically significant differences from the control group.

only slight inhibitory effect was seen after single treatment (Fig. 3).

\section{Effect of the combination of thiacremonone and docetaxel on apoptotic cell death in prostate cancer cells}

Cell death contributes to the cell growth inhibition. To further characterize the apoptotic cell death by the combination of thiacremonone and docetaxel, we evaluated changes in the chromatin morphology in prostate cancer cells using DAPI staining. We also performed TUNEL staining assays, and then double labeled (DAPI-stained TUNEL-positve cells) cells were analyzed by fluorescence microscopy. Apoptotic cells number (DAPI-stained TUNELpositive cells per high power field, $\times 200$ ) of prostate cancer cells was significantly increased by the combination of thiacremonone with docetaxel. In the combination study, $50 \mu \mathrm{g} /$ $\mathrm{ml}$ thiacremonone and $5 \mathrm{nM}$ docetaxel combination treat- ment resulted in about $41 \%$ apoptotic cells in PC-3 cancer cells and in 33\% DU145 cancer cells, whereas thiacremonone and docetaxel alone treatment induced apoptotic cell death about $10-20 \%$ in each cells (Fig. 4).

\section{Thiacremonone augmented docetaxel-induced the expression of apoptotic regulatory proteins}

To identify the mechanism of enhanced prostate cancer cell growth inhibition and apoptotic response by the thiacremonone and docetaxel combination treatment, we next assessed the expression of pro-and anti-apoptotic proteins by Western blotting. Cells were treated with thiacremonone $(50 \mu \mathrm{g} / \mathrm{ml})$ and docetaxel $(5 \mathrm{nM})$ or the combination for $24 \mathrm{~h}$, and their whole-cell extract were subjected to Western blotting. Our data showed that the combination treatment substantially inhibited the expression levels of the anti-apoptotic protein, but enhanced the expression of 
A

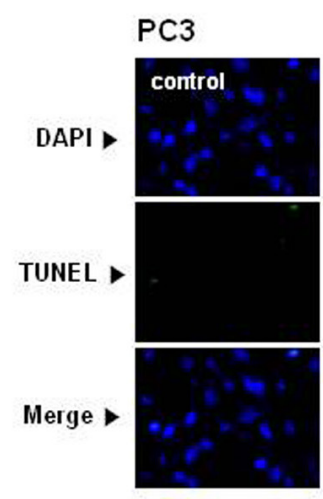

DU145

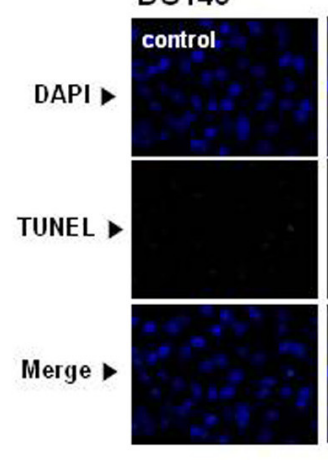

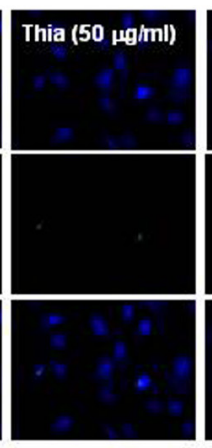
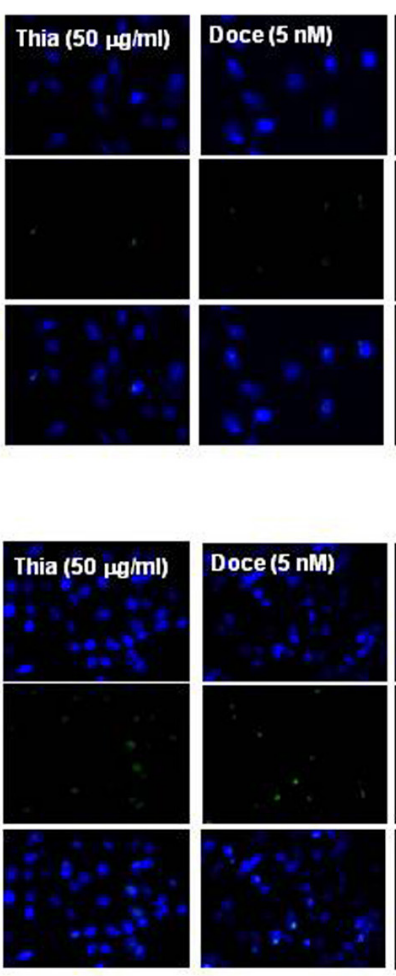

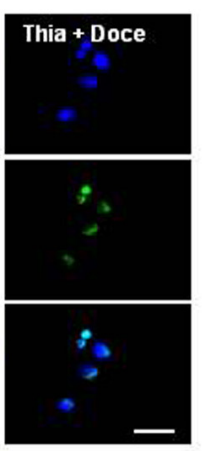

B

PC3

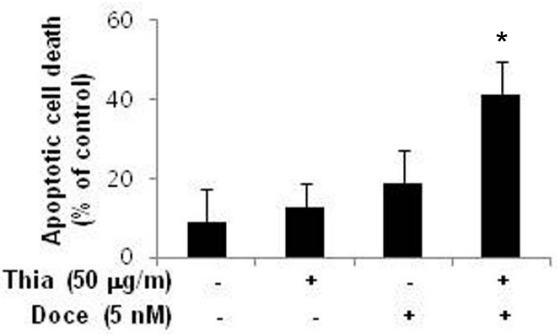

\section{DU145}

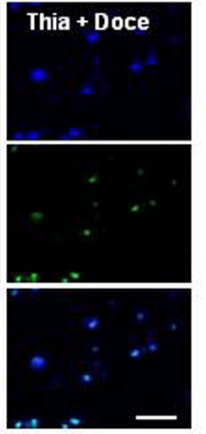

Fig. 4. Apoptotic cell death of prostate cancer cells by the combination treatment of thiacremonone and docetaxel. Prostate cancer cells were co-treated with $50 \mu \mathrm{g} / \mathrm{ml}$ thiacremonone or $5 \mathrm{nM}$ docetaxel or combination of thiacremonone and docetaxel for $24 \mathrm{~h}$. (A) Total number of cells in a given area was determined by using DAPI nuclear staining (Upper panels). Apoptotic cells were examined by fluorescence microscopy after TUNEL staining (fluorescent microscopy) (middle panels). (B) The apoptotic index was determined as the DAPI-stained TUNEL-positive cell number counted per high power field. Values are mean \pm S.D. of three experiments, with triplicate of each experiment. ${ }^{*} p<0.05$ indicates statistically significant differences from the control group. Bar indicates $50 \mu \mathrm{M}$.

PC3

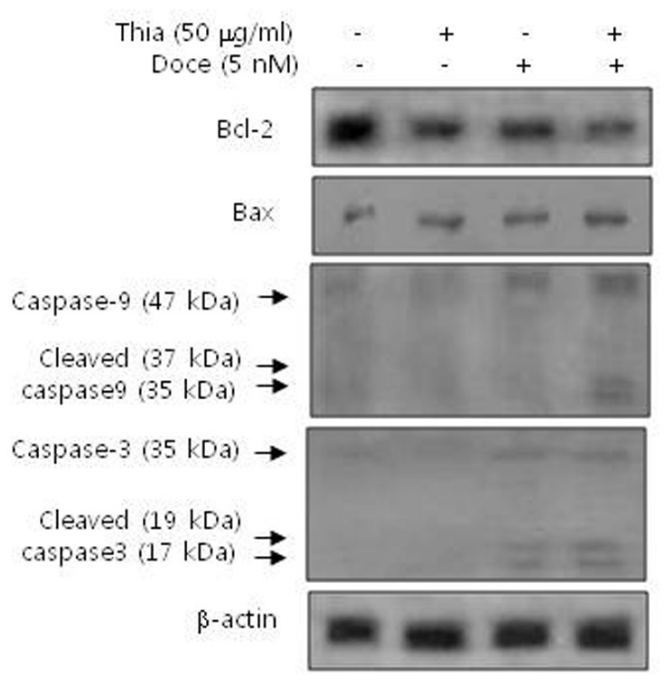

DU145

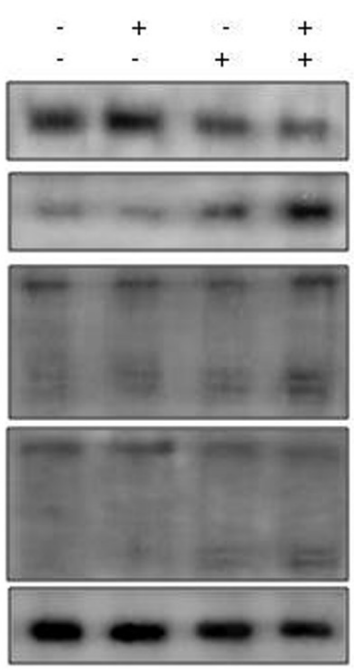

Fig. 5. Expression of apoptosis-related proteins of prostate cancer cells by the combination treatment of thiacremonone and docetaxel. Prostate cancer cells were co-treated with $50 \mu \mathrm{g} / \mathrm{ml}$ thiacremonone or $5 \mathrm{nM}$ docetaxel or combination of thiacremonone and docetaxel for $24 \mathrm{~h}$. Equal amounts of total proteins (50 $\mu \mathrm{g} /$ lane) were subjected to $12 \%$ SDS-PAGE. Expression of Bax, Caspase 3, Caspase 9, Bcl-2 and $\beta$ actin was detected by western blotting using specific antibodies. $\beta$-actin protein here was used as an internal control. Each blot is representative of three independent experimental resuIts. 
pro-apoptotic proteins. Expression of Bax, and active form of caspases-3 (cleaved caspase-3, 17 and $19 \mathrm{kDa}$ ), caspase- 9 (cleaved caspase- 9,35 and $37 \mathrm{kDa}$ ) was much greatly increased by the treatment of the combination of thiacremonone and docetaxel compared to that by single treatment. Our data also showed that the combination treatment significantly inhibited levels of $\mathrm{Bcl}-2$ expression compared to that by the single treatment (Fig. 5).

\section{DISCUSSION}

Docetaxel, a semi-synthetic member of the taxane family, has potential activity against human solid tumors including prostate cancers (Diaz-Rubio, 2004). However, the use of high-dose docetaxel induced significant toxicity (Tedesco et al., 2004; Sun et al., 2007), but low or moderate doses of docetaxel have no significant anti-cancer activity in patients (Ryan et al., 2002). To overcome these disadvantages, the combination therapy using conventional chemotherapeutic agents with dietary supplements as well as phytotherapeutic agents has been suggested as possible way to improve anti-cancer efficacy with lower toxicity. For examples, resveratrol or propolis in combination with vinorelbine showed a potential useful treatment for DU145 prostate cancer via the increase cell cycle control reinforcing cell growth inhibition (Scifo et al., 2006). Shigemura et al. reported that honokiol, a natural plant product, enhanced inhibition of the bone metastatic growth of human prostate cancer cells by docetaxcel (Shigemura et al., 2007). In addition, the combination of docetaxel, vinorelbine and oral estramustine was a well-tolerated regimen with high biochemical and objective response rates in patients with androgen-resistant prostate cancer (ARPC) (Rosenberg et al., 2009). Very similar to our finding, garlic-derived S-allylmercaptocysteine augmented docetaxel-induced effect on growth inhibition of cultured PC3 and DU145 cells, and this combination effect was greater and synergistic (Howard et al., 2008).

Most reports suggest that intrinsically or constitutively activated NF-kB may be critical in the development of drug resistance and survival signals that counteract apoptosis in cancer cells (Wang et al., 1996; Waddick and Uckun, 1999). Prevention of NF-kB activation, therefore, may represent a promising opportunity for widening therapeutic windows in translational cancer research (Millikan et al., 2001). NF-kB is the most reliable target of the combination chemotherapeutic treatment. Thus, we speculate that inhibition of NF-kB by the combination of thiacremonone and docetaxel is a profound contributor to the increase of sus- ceptibility of cancer cells. In fact, we found that constitutively activation of NF-KB activity was slightly decreased by the docetaxel and thiacremonone alone treatmenrt, but NF-kB activity was completely abrogated by the combination treatment. Agreement with our results, several combinations of therapeutic treatments have shown to enhance cancer cell susceptibility through coordinating inhibition of NF-kB (Pares et al., 1998; Qadan et al., 2001; Singh et al., 2002). Curcumin and TRAIL combination regimen was found to be the better effective treatment for inhibiting the growth of PC3 xenografts compared to curcumin or tumor necrosis factor-related apoptosis-inducing ligand (TRAIL) monotherpy through significant reduction in NF-kB in tumor tissue (Andrzejewski et al., 2008). It was also found that curcumin with beta-phenylethyl isothiocyanate (PEITC) additively inhibited NF- $\mathrm{kB}$ activity, and exerts their additive inhibitory effects on cell growth of tumor cells (Kim et al., 2006). Docosahexaenoic acid (DHA) also synergistically enhanced the cytotoxic effect of docetaxel in prostate cancer cells through suppression of genes involved in the NF-kB pathway (Shaikh et al., 2008). Sulindac enhances arsenic trioxide-mediated apoptosis in HCT116 colon cancer cells through the decrease NF- $k B$ activity after combination treatment (Qadan et al., 2001). We previously also found the synergistic effect of the combination of thiacremonone and docetaxel in NF-kB activity and colon cancer cell growth inhibition (Ban et al., 2009). Thus, the inactivation of NF- $\mathrm{KB}$ by the combination of thiacremonone and docetaxel could be significant in the combination effect on prostate cancer cell growth inhibition.

The exact mechanisms how the combination of thiacremonone and docetaxel can inhibit NF-kB, and thus inhibit cancer cell growth are not clear. Multiple signal pathways in the activation of NF-kB could be prevented by coordination of the combination. Down stream target gene expression by NF-kB is implicated in the sensitization of cancer cells to chemotherapeutic agents. It is well known that $\mathrm{NF}-\mathrm{kB}$ mediated expression of Bcl-2, IAP1/2 and Survivin protects cancer cell growth from apoptosis whereas expression of Bax and caspase- 3 and 9 inhibits cancer cell growth and induces apoptosis (Barkett and Gilmore, 1999; Chuang et al., 2002). The present data showed that the combination therapy regulated expression of these NF-kB target genes. Therefore, it is possible that the alternation of NF-kB target gene expression could be inhibited in growth. Taken together, these results suggest that the combination of thiacremonone and docetaxel can be a promising regimen for the treatment of prostate cancer cells. 


\section{ACKNOWLEDGMENTS}

This work was supported by the research grant of the Chungbuk National University in 2008.

\section{REFERENCES}

Andrzejewski, T., Deeb, D., Gao, X., Danyluk, A., Arbab, A. S., Dulchavsky, S. A. and Gautam S. C. (2008). Therapeutic efficacy of curcumin/TRAIL combination regimen for hormone-refractory prostate cancer. Oncol. Res. 17, 257-267.

Ban, J. O., Lee, H. S., Jeong, H. S., Song, S., Hwang, B. Y., Moon, D. C., Yoon, D. Y., Han, S. B. and Hong, J. T. (2009). Thiacremonone augments chemotherapeutic agent-induced growth inhibition in human colon cancer cells through inactivation of nuclear factor-\{kappa\}B. Mol. Cancer Res. 7, 870-879.

Ban, J. O., Yuk, D. Y., Woo, K. S., Kim, T. M., Lee, U. S., Jeong, H. S., Kim, D. J., Chung, Y. B., Hwang, B. Y., Oh, K. W. and Hong, J. T. (2007) Inhibition of cell growth and induction of apoptosis via inactivation of NF-kappaB by a sulfurcompound isolated from garlic in human colon cancer cells. $J$. Pharmacol. Sci. 104, 374-383.

Baker, J., Ajani, J., Scotté, F., Winther, D., Martin, M., Aapro, M. S. and von Minckwitz, G. (2009). Docetaxel-related side effects and their management. Eur. J. Oncol. Nurs. 13, 4959.

Barkett, M. and Gilmore, T. D. (1999). Control of apoptosis by Rel/NF-кB transcription factors. Oncogene 18, 6910-6924.

Chuang, S. E., Yeh, P. Y. and Lu, Y. S. (2002). Basal levels and patterns of anticancer drug-induced activation of nuclear factor-kappaB (NF-kappaB), and its attenuation by tamoxifen, dexamethasone, and curcumin in carcinoma cells. Biochem. Pharmacol. 63, 1709-1716.

Diaz-Rubio, E. (2004). New chemotherapeutic advances in pancreatic, colorectal, and gastric cancers. Oncologist 282294.

Dong, Q. G., Sclabas, G. M. and Fujioka, S. (2002). The function of multiple lkappaB: NF-kappaB complexes in the resistance of cancer cells to Taxol-induced apoptosis. Oncogene 21, 6510-6519.

Howard, E. W., Lee, D. T., Chiu, Y. T., Chua, C. W., Wang, X. and Wong, Y. C. (2008). Evidence of a novel docetaxel sensitizer, garlic-derived S-allylmercaptocysteine, as a treatment option for hormone refractory prostate cancer. Int. J. Cancer 122, 1941-1948.

Hwang, I. K., Woo, K. S., Kim, D. J., Hong, J. T., Hwang, B. Y., Lee, Y. R. and Jeong, H. S. (2007). Isolation and Identification of an Antioxidant Substance from Heated Garlic (Allium sativum L.). Food Sci. Biotechnol. 16, 963-966

Kelloff, G. J. (2000). Perspectives on cancer chemoprevention research and drug development. Adv. Cancer Res. 78, 199334.

Kim, J. H., Xu, C., Keum, Y. S., Reddy, B., Conney, A. and Kong, A. N. (2006) Inhibition of EGFR signaling in human prostate cancer PC-3 cells by combination treatment with beta-phenylethyl isothiocyanate and curcumin. Carcinogenesis 27, 475-482.

Kim, S. M., Lee, S. Y., Yuk, D. Y., Moon, D. C., Choi, S. S., Kim,
Y., Han, S. B., Oh, K. W. and Hong, J. T. (2009). Inhibition of NF-kappaB by ginsenoside Rg3 enhances the susceptibility of colon cancer cells to docetaxel. Arch. Pharm. Res. 32, 755-765.

Kwon, O. C., Woo, K. S., Kim, T. M., Kim, D. J., Hong, J. T. and Jeong, H. S. (2006). Physicochemical characteristics of garlic (Allium sativum L.) on the high temperature and pressure treatment. Korean J. Food Sci. Technol. 38, 331-336.

Millikan, R., Baez, L., Banerjee, T., Wade, J., Edwards, K., Winn R., Smith, T. L. and Logothetis, C. (2001). Randomized phase 2 trial of ketoconazole and ketoconazole/doxorubicin in androgen independent prostate cancer. Urol. Oncol. 6, 111-115.

Nakagawa, H., Tsuta, K., Kiuchi, K., Senzaki, H., Tanaka, K., Hioki, K. and Tsubura, A. (2001). Growth inhibitory effects of diallyl disulfide on human breast cancer cell lines. Carcinogenesis 22, 891-897.

Ojima, I., Kuduk, S. D., Slater, J. C., Gimi, R. H. and Sun, C. M. (1996). Syntheses of new fluorine-containing taxoids by means of $\beta$-lactam synthon method. Tetrahedron 52, 209224.

Ortiz, M. A., Bayon, Y., Lopez-Hernandez, F. J. and Piedrafita F. J. (2002). Retinoids in combination therapies for the treatment of cancer: mechanisms and perspectives. Drug Resist. Updat. 5, 162-175.

Palayoor, S. T., Youmell, M. Y., Calderwood, S. K., Coleman, C. N. and Price, B. D. (1999). Constitutive activation of lkappa B alpha and NF-kappB in prostate cancer cells is inhibited by ibuprofen. Oncogene 18, 7389-7394.

Pares, A., Planas, R., Torres, M., Caballeria, J., Viver, J. M., Acero, D., Panes, J., Rigau, J., Santos, J. and Rodes, J. (1998). Effects of silymarin in alcoholic patients with cirrhosis of the liver: results of a controlled, double-blind, randomized and multicenter trial. J. Hepatol. 28, 615-621.

Qadan, L. R., Perez-Stable, C. M., Anderson, C., D'Ippolito, G., Herron, A., Howard, G. A. and Roos, B. A. (2001). 2Methoxyestradiol induces G2-M arrest and apoptosis in prostate cancer. Biochem. Biophys. Res. Commun. 285, 1259-1266.

Rosenberg, J. E., Ryan, C. J., Weinberg, V. K., Smith, D. C., Hussain, M., Beer, T. M., Ryan, C. W., Mathew, P., Pagliaro, L. C., Harzstark, A. L., Sharib, J. and Small, E. J. (2009). Phase I study of ixabepilone, mitoxantrone, and prednisone in patients with metastatic castration-resistant prostate cancer previously treated with docetaxel-based therapy: a study of the department of defense prostate cancer clinical trials consortium. J. Clin. Oncol. 27, 2772-2778.

Ryan, D. P., Kulke, M. H., Fuchs, C. S., Grossbard, M. L., Grossman, S. R., Morgan, J. A., Earle, C. C., Shivdasani, R., Kim, H., Mayer, R. J. and Clark, J. W. (2002). A Phase II study of gemcitabine and docetaxel in patients with metastatic pancreatic carcinoma. Cancer 94, 97-103.

Sabayan, B., Foroughinia, F. and Chohedry, A. (2007). A postulated role of garlic organosulfur compounds in prevention of valproic acid hepatotoxicity. Med. Hypotheses. 68, 512-514.

Sarafraz, M. and Ahmadi, K. (2008). Paraclinical evaluation of side-effects of Taxanes on auditory system. Acta. Otorhinolaryngol. Ital. 28, 239-242.

Scifo, C., Milasi, A., Guarnera, A., Sinatra, F. and Renis, M. (2006). Resveratrol and propolis extract: an insight into the morphological and molecular changes induced in DU145 
cells. Oncol. Res. 15, 409-421.

Shaikh, I. A., Brown, I., Schofield, A. C., Wahle, K. W. and Heys, S. D. (2008). Docosahexaenoic acid enhances the efficacy of docetaxel in prostate cancer cells by modulation of apoptosis: the role of genes associated with the NF-kappaB pathway. Prostate 68, 1635-1646.

Shigemura, K., Arbiser, J. L., Sun, S. Y., Zayzafoon, M. Johnstone, P. A., Fujisawa, M., Gotoh, A., Weksler, B., Zhau, H. E. and Chung, L. W. (2007). Honokiol, a natural plant product, inhibits the bone metastatic growth of human prostate cancer cells. Cancer 109, 1279-1289.

Singh, R. P., Tyagi, A. K., Zhao, J. and Agarwal, R. (2002). Silymarin inhibits growth and causes regression of established skin tumors in SENCAR mice via modulation of mitogen-activated protein kinases and induction of apoptosis. Carcinogenesis Lond. 23, 499-510.

Sporn. M. B. and Suh. N. (2000). Chemoprevention of cancer. Carcinogenesis Lond. 21, 525-530.

Sun, L. C., Luo, J., Mackey, L. V., Fuselier, J. A. and Coy, D. H. (2007). A conjugate of camptothecin and a somatostatin analog against prostate cancer cell invasion via a possible signaling pathway involving PI3 K/Akt, alphaVbeta3/alphaVbeta5 and MMP-2/-9. Cancer Lett. 246, 157-166.

Tedesco, K. L., Thor, A. D., Johnson, D. H., Shyr, Y., Blum, K. A., Goldstein, L. J., Gradishar, W. J., Nicholson, B. P., Merkel, D. E., Murrey, D., Edgerton, S. and Sledge, G. W.
(2004). Docetaxel combined with trastuzumab is an active regimen in HER-2 3 + overexpressing and fluorescent in situ hybridization-positive metastatic breast cancer: a multi-institutional phase II trial. J. Clin. Oncol. 15, 1071-1077.

Uzzo, R. G., Leavis, P. and Hatch, W. (2002). Zinc inhibits nuclear factorkappa B activation and sensitizes prostate cancer cells to cytotoxic agents. Clin. Cancer Res. 8, 3579-3583.

Waddick, K. G. and Uckun, F. M. (1999). Innovative treatment programs against cancer: II. Nuclear factor- $\mathrm{KB}(\mathrm{NF}-\mathrm{\kappa B})$ as a molecular target. Biochem. Pharmacol. 57, 9-17.

Wang, C. Y., Mayo, M. W. and Baldwin, A. S. (1996). TNF-and cancer therapy-induced apoptosis: potentiation by inhibition of NF-кB. Science 274, 784-787.

Wang, W. and Cassidy, J. (2003). Constitutive nuclear factorkappa B mRNA, protein overexpression and enhanced DNA-binding activity in thymidylate synthase inhibitorresistant tumour cells. Br. J. Cancer 88, 624-629.

Yance, D. R. and Sagar, S. M. (2006). Targeting angiogenesis with integrative cancer therapies. Integr. Cancer Ther. 5, 9-29.

Zhang, H., Morisaki, T. and Nakahara, C. (2003). PSK-mediated NF-kappaB inhibition augments docetaxel-induced apoptosis in human pancreatic cancer cells NOR-P1. Oncogene 22, 2088-2096. 